\title{
Horizontal gene transfer and recombination in Streptococcus dysgalactiae subsp. equisimilis
}

\author{
Celia L. McNeilly ${ }^{1}$ and David J. McMillan' ${ }^{2}$ \\ Bacterial Pathogenesis Laboratory, QIMR Berghofer Medical Research Institute, Herston, QLD, Australia \\ 2 Inflammation and Healing Research Cluster, School of Health and Sport Sciences, University of the Sunshine Coast, Maroochydore, QLD, Australia
}

\section{Edited by:}

Claudio Palmieri, Polytechnic

University of Marche, Italy

Reviewed by:

William M. McShan, University of Oklahoma Health Sciences Center. USA

Maria C. Di Luca, University

Hospital of North Norway, Norway

*Correspondence:

David J. McMillan, Inflammation and Healing Research Cluster,

School of Health and Sport

Sciences, University of the

Sunshine Coast, 90 Sippy Downs

Drive, Sippy Downs, Maroochydore,

QLD 4556, Australia

e-mail:david.mcmillan@usc.edu.au
Streptococcus dysgalactiae subsp. equisimilis (SDSE) is a human pathogen that colonizes the skin or throat, and causes a range of diseases from relatively benign pharyngitis to potentially fatal invasive diseases. While not as virulent as the close relative Streptococcus pyogenes the two share a number of virulence factors and are known to coexist in a human host. Both pre- and post-genomic studies have revealed that horizontal gene transfer (HGT) and recombination occurs between these two organisms and plays a major role in shaping the population structure of SDSE. This review summarizes our current knowledge of HGT and recombination in the evolution of SDSE.

Keywords: Streptococcus dysgalactiae subsp. equisimilis, Streptococcus pyogenes, horizontal gene transfer recombination, M-protein, bacteriophage, integrative conjugative element

\section{INTRODUCTION}

Streptococcus pyogenes (group A Streptococcus, GAS) and Streptococcus dysgalactiae subsp. equisimilis (SDSE, human group C and $G$ streptococci) are the two most common $\beta$-hemolytic streptococci recovered from humans. Along with Streptococcus canis, a bacterium causing infections in dogs and sometime humans (Galperine et al., 2007) they form a separate phylogenetic branch of the $\beta$-hemolytic streptococci (Facklam, 2002; Lefebure et al., 2012). GAS is a major pathogen of humans, and the cause of approximately half a million deaths each year. Diseases associated with GAS infection range from self-limiting throat and skin infections to the potentially fatal rheumatic fever (RF), rheumatic heart disease (RHD), and serious invasive diseases. In contrast, SDSE is generally of lesser virulence, and was once considered to be an opportunistic pathogen. Multiple studies have conclusively shown, that with the exception of RF/RHD, infection with this organism can result in elaboration of the same diseases as caused by GAS infection (Efstratiou, 1997; Chhatwal et al., 2006; O'Loughlin et al., 2007; Broyles et al., 2009). Circumstantial evidence for a link between SDSE and RF has also been provided in one instance (Haidan et al., 2000). With the similarities in disease association, colonization of the same host niches (i.e., throat and skin), and close evolutionary relationship it is unsurprising that these two species possess homologous virulence genes. Indeed, many of the classical virulence genes of GAS, such as the emm-genes and streptokinase, are also present in SDSE. While such genes are mostly paralogs inherited from a common ancestor, there is evidence of the transfer of virulence genes, and indeed house-keeping genes between the two species. In GAS, the acquisition of virulence genes by horizontal gene transfer (HGT) is associated with changes in virulence of some lineages (Cole et al., 2011), and this may also be true for SDSE. This review provides a concise summary of our current knowledge of HGT and recombination involving SDSE.

\section{SDSE VIRULENCE FACTORS AND HGT M-PROTEIN}

The $\mathrm{M}$ protein, encoded by the emm-gene, is a critical virulence factor of GAS that is also present in SDSE. Variations in the gene corresponding to the amino-terminal part of the M-protein are also used to classify individual GAS and SDSE isolates into emm-types. More than 200 GAS emm-types and 50 separate SDSE emm-types have been described (Beall et al., 1996; Cohen-Poradosu et al., 2004). As these emm-types are species specific, their presence in a different species, or in different genetic backgrounds of the same species can be used to infer HGT involving this gene. The first such indications of interspecies HGT were provided by Maxted and Potter (1967), who showed crossreactivity between a group $\mathrm{G}$ streptococcal isolate and typing sera raised against the GAS M12 protein. Several decades later the first genetic evidence for HGT of the emm-gene was presented (Simpson et al., 1987, 1992; Sriprakash and Hartas, 1996). More recently, multi-locus sequence typing (MLST) studies have provided new insights into extent of both inter and intra-species emm-gene HGT in SDSE (Ahmad et al., 2009; McMillan et al., 2010, 2011). By examining genetic differences in house-keeping genes that theoretically do not undergo HGT, MLST provides a mechanism for assessing the evolutionary relationships between 
clonal and distantly related isolates of the same species. Overlaying emm-type information onto this MLST data provides a means to predict instances of both intra-species and inter-species HGT that is not feasible using older techniques (Enright et al., 2001). Using this approach, HGT of the emm-gene in SDSE has been revealed to be much more common than predicted, with three separate population studies reporting the presence of the same SDSE emm-gene in distantly related SDSE isolates or multiple emm-genes in the same genetic background (Ahmad et al., 2009; McMillan et al., 2010, 2011). GAS emm-genes genes were also present in some SDSE isolates in these studies. While emm-gene HGT has also been reported in GAS (Bessen et al., 2008), it appears to be more frequent in SDSE. Together the data suggest that some caution must be taken when using emm-sequencing to imply genetic relatedness of SDSE isolates that are temporally or geographically unrelated.

The results of these studies open questions as to how and why such events are occurring. Using bioinformatics analyses, Panchaud et al. (2009) predicted the emm-gene to be part of an ancient pathogenicity island consisting of approximately 40 genes in GAS. The group went on to identify a natural isolate specifically lacking this region, and also demonstrated deletion of the region in laboratory, providing in vitro support for their bioinformatic findings. It is tempting to suggest that the emm-gene in SDSE is also part of the same pathogenicity island. Indeed a genomic comparison shows evidence for a homologous mobile genetic element (MGE) in SDSE. However, the emm-gene is not part of this island, and is located in a distant part of the chromosome (Suzuki et al., 2011). Thus while SDSE may acquire GAS emmgenes through a mechanism involving this pathogenicity island, it cannot be invoked as a hypothesis of how SDSE emm-genes are distributed through the population.

In GAS, the M protein is both an inhibitor of opsonophagocytosis and an adhesin (Bessen et al., 1989; Cunningham, 2000). These attributes are achieved through the protein's ability to act as a ligand for multiple extracellular matrix and immune-systemassociated proteins including fibronectin, fibrinogen, albumin, collagen, antibody, and C4b binding protein (Horstmann et al., 1988; Akesson et al., 1994; Johnsson et al., 1996, 1998; Cue et al., 2001; Dinkla et al., 2003). Apart from opsono-inhibitory activity, not all M-proteins possess all these functions, which may be a factor in the niche specialization of some GAS emmtypes. SDSE M-proteins are known to inhibit opsonophagocytosis (Bisno et al., 1987) and reported to bind collagen (Barroso et al., 2009). The latter property has been suggested to be involved in the pathogenesis of rheumatic heart fever following GAS infection (Dinkla et al., 2007). Based on data from multiple GAS Mproteins we would not expect all SDSE proteins to have the same ligand binding properties, and switching of emm-genes from one to another may be a strategy for attainment of new virulence properties. However, we have no evidence that expression of different M-proteins by SDSE alters pathogenesis of individual lineages (Ikebe et al., 2004; Pinho et al., 2006). As the aminoterminus of the M-protein of GAS is also the target of emm-type specific bactericidal antibodies (Beachey et al., 1981; Beachey and Seyer, 1986), switching emm-genes may simply be a mechanism for avoidance of emm-type specific antibody responses.

\section{OTHER VIRULENCE GENES}

Horizontal gene transfer and recombination are also apparent in other SDSE virulence genes. $g f b A$ and $s f b I$, genes encoding fibronectin-binding proteins in SDSE and GAS are part of the fibronectin-collagen-T antigen (FCT) locus. The locus also includes genes that encode a transcriptional regulator, pilusassociated proteins and other extracellular matrix binding proteins (Mora et al., 2005; Lizano et al., 2007). Recombination within the aromatic amino acid rich (Aro) domain of both GfbA and SfbI gives rise to so-called mosaic proteins. In several instances, these proteins include mosaic domains derived from both GAS and SDSE (Towers et al., 2004). Streptokinase (skg) is another SDSE gene with a mosaic structure. Streptokinase interacts with plasminogen ultimately resulting in the formation of the serine protease plasmin. Plasmin activity subsequently assists the dissemination of streptococci (Ben Nasr et al., 1994). The corresponding ska genes in GAS are also mosaic in nature (Kapur et al., 1995; Kalia and Bessen, 2004). Again there is evidence for interspecies transfer of domains within the streptokinase gene (Tewodros et al., 1996; Kalia and Bessen, 2004). Functionally, streptokinase variants display different plasminogen activation characteristics (McArthur et al., 2008). While variations in ska have also been linked to tissue tropism (Kalia and Bessen, 2004) and nephritis in GAS, no attempt to find similar associations has been attempted for SDSE. The mosaic nature of $g f b A, s k g$ and their counterparts in GAS suggest the mechanism responsible for recombination is different to that associated with emm-gene HGT. Nevertheless, recombination with foreign DNA can only take place after a HGT event. Parts of the FCT locus are reported to be highly similar to sequences present in genomic islands in $S$. agalactiae (Beres and Musser, 2007), providing some evidence of a potential mechanism for the transfer of FCT-associated genes in other streptococcal species. The mosaic nature of these genes resembles in some respects segmentally variable genes (SVGs; Zheng et al., 2004). SVGs contain highly variable regions within well-conserved regions, and have been suggested to account for $10-20 \%$ of some bacterial genomes. The highly variable regions are suggested to be to be involved in interaction with other molecules, and be under diversifying selection pressure. As the fibronectin-binding genes and streptokinase of streptococci also interact with host molecules, recombination in these genes may be a similar strategy for diversification of the function of these genes.

DrsG provide a contemporary example of an SDSE virulence gene that is most likely part of an MGE (Minami et al., 2011; Oppegaard et al., 2014; Smyth et al., 2014). DrsG is a homolog of streptococcal inhibitor of complement (SIC) and distantly related SIC (DRS), related proteins that are secreted by GAS. sic and drs are only present in four of the more than 200 GAS emm-types. In emm $1, e m m 12$, and emm55 GAS, sic and drs are part of the mga locus. However, in emm57 GAS, the gene sits between $r p s \mathrm{U}$ and a gene encoding an ATP-binding cassette $(\mathrm{ABC})$ transporter (Binks et al., 2003). The non-coding DNA flanking sic in emm57 is highly similar to that observed which flanks sic in M1 GAS, suggesting that is was acquired via HGT from emm 1 GAS. In contrast, $d r s G$ has been identified in 19 of the approximately 50 SDSE emm-types (Minami et al., 2011). However, not all isolates within a $d r s G$ - 
positive emm-type possess the gene. $d r s \mathrm{G}$ is also highly conserved at both the nucleotide and amino acid level across all emm-types, with an identity greater than $95 \%$. The gene adjacent to $d r s \mathrm{G}$ in some SDSE isolates is also an MGE-related gene (Smyth et al., 2014). The data suggests that whereas sic and $d r s$ appear to have entered the emm 1 , emm 12 , and emm55 GAS populations prior to segregation into specific emm-types, $d r s G$ was acquired later in the evolution of individual SDSE emm-types. Given the high level of identity of $d r s G$ in different emm-types it is also reasonable to hypothesize that the gene may be part of an MGE that is being transferred through the SDSE population. Functionally, DrsG is more related to DRS than SIC. Whereas SIC is an inhibitor of complement (Akesson et al., 1996; Fernie-King et al., 2001), neither DRS or DrsG have this property (Smyth et al., 2014). However, all three proteins are inhibitory to the antimicrobial activity of LL-37, a cathelicidin present on mucosal surfaces (Lai and Gallo, 2009) colonized by streptococci. Both SIC and DRS are also reported to be inhibitory to other antimicrobial peptides (AMPs; Fernie-King et al., 2004; Frick et al., 2011), properties which have yet to be tested for DrsG. Together these results suggest that inhibition of AMP activity is the major function of this family of proteins. By preventing AMP mediated killing, such activity theoretically improves the colonization success of streptococci relative GAS and SDSE lacking these genes.

\section{TRANSFER OF ANTIBIOTIC RESISTANCE GENES}

Perhaps the HGT events in SDSE with the greatest clinical impact currently involve antibiotic resistance genes. Fluoroquinolones are a class of antibiotic proscribed for treatment of streptococcal infection that function by inhibiting DNA gyrase (gyrA) and topoisomerase IV (parC). Resistance to fluoroquinolones has been reported in several streptococcal species (Kawamura et al., 2003; Reinert et al., 2004; Powis et al., 2005; Wehbeh et al., 2005) including SDSE (Biedenbach et al., 2006; Pletz et al., 2006), and occurs due to point mutations in the quinolone resistance determining regions (QRDR) of the genes encoding these proteins or through active drug efflux mechanisms. Similar to other genes described in this review, it appears that HGT and recombination involving these genes has occurred multiple times (Pletz et al., 2006; Duesberg et al., 2008).

\section{HGT AND RECOMBINATION INVOLVING HOUSE-KEEPING GENES}

The SDSE MLST schemes targets seven genes, glucose kinase ( $g k i)$, glutamine transport protein $(g t r)$, glutamate racemase (murI), DNA mismatch repair protein (mutS), transketolase $(\operatorname{rec} P)$, xanthine phosphoribosyltransferase $(x p t)$, and acetoacetyl-coathioloase $(a t o B)$. With the exception of ato $B$ the genes used for MLST in SDSE are the same as used for the GAS MLST scheme. Analogous to the HGT involving emm-genes the presence of GAS MLST alleles in SDSE provides strong evidence for the transfer of these theoretically fixed non-MGE-related genes (Ahmad et al., 2009; McMillan et al., 2010, 2011). In most instances, entire allelic regions were replaced with the corresponding regions from other SDSE isolates, GAS or even $S$. agalactiae. In some instances, evidence of recombination within the alleles, similar to what has been reported for $g f b A$ and streptokinase was also observed. For instance, the gki12 and gki4 alleles of SDSE appear to be hybrids of separate SDSE and GAS alleles. These studies also revealed that, at least for the genes used in MLST, it is recombination rather that point mutation that gives rise to diversity in the population.

The mechanisms that result in HGT of house-keeping genes in SDSE are yet to be determined. In S. agalactiae, transfer of large sections of chromosomal DNA has been reported (Brochet et al., 2008). They demonstrated that erythromycin marked DNA segments up to $300 \mathrm{~kb}$ long could be transferred from a donor to recipient group B streptococci (GBS) strains via conjugation. Moreover, they were able to demonstrate that these transfers could be initiated from multiple sites. In some instances, these transfers are directly associated with genomic islands carrying genes involved in HGT. Given that S. agalactiae and SDSE are relatively closely related, and the high rate of recombination, it is tempting to speculate that a similar events are occurring is SDSE. If this hypothesis is correct, it would explain both the transfer of house-keeping genes and non-MGE-related virulence genes.

\section{MOBILE GENETIC ELEMENTS OF SDSE}

The transfer of bacteriophage between GAS and group G streptococci was the first demonstration of interspecies HGT between these species (Colon et al., 1971). In the post-genomic era, we now know SDSE to be polylysogenic. Of the small number of genomes thus far sequenced the number of phage present range from one in SDSE RE378 to six in GGS_124 and AC-2713 (Watanabe et al., 2013) demonstrating their importance in promoting genetic diversity in the species. Molecular epidemiological studies have shown GAS-related superantigen genes to be absent or very rare in SDSE (Sachse et al., 2002; Kalia and Bessen, 2003; Davies et al., 2007; Tsai et al., 2013; Lo and Cheng, 2014) suggesting bacteriophage mediated HGT events between GAS and SDSE to be rare.

The first integrative conjugative element (ICE) in SDSE was described by Davies et al. (2009). ICESde3396 is a one of a group of related ICEs whose members also include ICESa2603 in GBS, ICESde32457 in Streptococcus suis (Palmieri et al., 2011, 2012) and a second ICESde3396-like element in SDSE 5580 (Palmieri et al., 2013). These ICEs have a common integration site in the rplL gene and share common genes involved in excision, transfer, and integration into recipient genome. Each also harbors a set of accessory genes that impart unique phenotypic features such as resistance to metals, or antibiotic resistance. These accessory regions are mosaic in nature and are likely to be the result of multiple recombination events. The closest homologs of these accessory genes can be found in different streptococcal species, and even non-streptococci. In vitro transfer of representative ICEs from this group to multiple recipient species, including GAS, $S$. agalactiae. SDSE and S. pneumoniae has been demonstrated by different groups (Davies et al., 2009; Palmieri et al., 2013). Based on this data it is likely that ICEs are the major source of novel genes in the SDSE population. Recently Palmieri et al. (2013) also demonstrated that the ICESde3396-element was able to mobilize and transfer a non-self-transmissible plasmid containing an erythromycin resistance gene from SDSE to other streptococcal species. This mechanism appears to be novel in the streptococci, 
and could explain how similar plasmids are transferred in other streptococci. An unrelated ICE, region of difference 2 (RD2), has also been identified in SDSE (Sitkiewicz et al., 2011). RD2 was first identified in GAS and is also similar to sequences in S. agalactiae (Green et al., 2005; Beres and Musser, 2007). RD2 carries several genes encoding putative surface proteins, including R28. R28 is involved in GBS binding to host vaginal cells. As RD2positive GAS emm-types are also over-represented in puerperal infections the implication is that acquisition of RD2 has altered the pathogenesis of isolates within these emm-types.

\section{CONCLUSION}

Our knowledge of the population structure, molecular epidemiology and pathogenic mechanisms of SDSE are lacking when compared to GAS and other pathogenic streptococci. However, it is apparent that HGT and recombination play an important role in generating genetic diversity within the species. New phenotypic repertoires associated with HGT may occasionally give rise to clones with increased fitness that could conceivably become dominant strains, or have increased virulence. The scale of HGT varies from replacement of individual domains within a gene to large MGE-associated transfers. While both bacteriophage and ICEs contribute to genetic diversity, current evidence indicates that it is ICEs that provide most novel genes to the population. In the future, comparative genomic sequencing of large numbers of SDSE isolates will provide a much greater depth to our understanding of these events, and how this bacterium has, and continues to evolve.

\section{REFERENCES}

Ahmad, Y., Gertz, R. E. Jr., Li, Z., Sakota, V., Broyles, L. N., Van Beneden, C., et al. (2009). Genetic relationships deduced from emm and multilocus sequence typing of invasive Streptococcus dysgalactiae subsp. equisimilis and S. canis recovered from isolates collected in the United States. J. Clin. Microbiol. 47, 2046-2054. doi: 10.1128/JCM.00246-09

Akesson, P., Schmidt, K. H., Cooney, J., and Bjorck, L. (1994). M1 protein and protein $\mathrm{H}$ : IgGFc- and albumin-binding streptococcal surface proteins encoded by adjacent genes. Biochem. J. 300(Pt 3), 877-886.

Akesson, P., Sjoholm, A. G., and Bjorck, L. (1996). Protein SIC, a novel extracellular protein of Streptococcus pyogenes interfering with complement function. J. Biol. Chem. 271, 1081-1088. doi: 10.1074/jbc.271.2.1081

Barroso, V., Rohde, M., Davies, M. R., Gillen, C. M., Nitsche-Schmitz, D. P., Dinkla, K., et al. (2009). Identification of active variants of PARF in human pathogenic group C and group G streptococci leads to an amended description of its consensus motif. Int. J. Med. Microbiol. 299, 547-553. doi: 10.1016/j.ijmm.2009.04.004

Beachey, E. H., and Seyer, J. M. (1986). Protective and nonprotective epitopes of chemically synthesized peptides of the NH2-terminal region of type 6 streptococcal M protein. J. Immunol. 136, 2287-2292.

Beachey, E. H., Seyer, J. M., Dale, J. B., Simpson, W. A., and Kang, A. H. (1981). Type-specific protective immunity evoked by synthetic peptide of Streptococcus pyogenes M protein. Nature 292, 457-459. doi: 10.1038/292457a0

Beall, B., Facklam, R., and Thompson, T. (1996). Sequencing emm-specific PCR products for routine and accurate typing of group A streptococci. J. Clin. Microbiol. 34, 953-958.

Ben Nasr, A., Wistedt, A., Ringdahl, U., and Sjobring, U. (1994). Streptokinase activates plasminogen bound to human group $\mathrm{C}$ and $\mathrm{G}$ streptococci through M-like proteins. Eur. J. Biochem. 222, 267-276. doi: 10.1111/j.14321033.1994.tb18865.x

Beres, S. B., and Musser, J. M. (2007). Contribution of exogenous genetic elements to the group A Streptococcus metagenome. PLoS ONE 2:e800. doi: 10.1371/journal.pone. 0000800
Bessen, D., Jones, K. F., and Fischetti, V. A. (1989). Evidence for two distinct classes of streptococcal M protein and their relationship to rheumatic fever. J. Exp. Med. 169, 269-283. doi: 10.1084/jem.169.1.269

Bessen, D. E., Mcgregor, K. F., and Whatmore, A. M. (2008). Relationships between emm and multilocus sequence types within a global collection of Streptococcus pyogenes. BMC Microbiol. 8:59. doi: 10.1186/1471-2180-8-59

Biedenbach, D. J., Toleman, M. A., Walsh, T. R., and Jones, R. N. (2006). Characterization of fluoroquinolone-resistant beta-hemolytic Streptococcus spp. isolated in North America and Europe including the first report of fluoroquinoloneresistant Streptococcus dysgalactiae subspecies equisimilis: report from the SENTRY Antimicrobial Surveillance Program (1997-2004). Diagn. Microbiol. Infect. Dis. 55, 119-127. doi: 10.1016/j.diagmicrobio.2005.12.006

Binks, M., McMillan, D., and Sriprakash, K. S. (2003). Genomic location and variation of the gene for CRS, a complement binding protein in the M57 strains of Streptococcus pyogenes. Infect. Immun. 71, 6701-6706. doi: 10.1128/IAI.71.12.6701-6706.2003

Bisno, A. L., Craven, D. E., and Mccabe, W. R. (1987). M proteins of group G streptococci isolated from bacteremic human infections. Infect. Immun. 55, 753757.

Brochet, M., Rusniok, C., Couve, E., Dramsi, S., Poyart, C., Trieu-Cuot, P., et al. (2008). Shaping a bacterial genome by large chromosomal replacements, the evolutionary history of Streptococcus agalactiae. Proc. Natl. Acad. Sci. U.S.A. 105, 15961-15966. doi: 10.1073/pnas.0803654105

Broyles, L. N., Van Beneden, C., Beall, B., Facklam, R., Shewmaker, P. L., Malpiedi, P., et al. (2009). Population-based study of invasive disease due to betahemolytic streptococci of groups other than A and B. Clin. Infect. Dis. 48, 706712. doi: $10.1086 / 597035$

Chhatwal, G. S., McMillan, D. J., and Talay, S. R. (2006). "Pathogenicity factors in group C and G streptococci," in Gram-Positive Pathogens, 2nd Edn, eds V. A. Fischetti, R. P. Novick, J. J. Ferretti, D. A. Portnoy, and J. I. Rood (Washington, DC: ASM Press), 213-221.

Cohen-Poradosu, R., Jaffe, J., Lavi, D., Grisariu-Greenzaid, S., Nir-Paz, R., Valinsky, L., et al. (2004). Group G streptococcal bacteremia in Jerusalem. Emerg. Infect. Dis. 10, 1455-1460. doi: 10.3201/eid1008.030840

Cole, J. N., Barnett, T. C., Nizet, V., and Walker, M. J. (2011). Molecular insight into invasive group A streptococcal disease. Nat. Rev. Microbiol. 9, 724-736. doi: $10.1038 /$ nrmicro2648

Colon, A. E., Cole, R. M., and Leonard, C. G. (1971). Lysis and lysogenization of groups A, C, and G streptococci by a transducing bacteriophage induced from a group G Streptococcus. J. Virol. 8, 103-110.

Cue, D., Lam, H., and Cleary, P. P. (2001). Genetic dissection of the Streptococcus pyogenes M1 protein: regions involved in fibronectin binding and intracellular invasion. Microb. Pathog. 31, 231-242. doi: 10.1006/mpat.2001.0467

Cunningham, M. W. (2000). Pathogenesis of group A streptococcal infections. Clin. Microbiol. Rev. 13, 470-511. doi: 10.1128/CMR.13.3.470-511.2000

Davies, M. R., McMillan, D. J., Beiko, R. G., Barroso, V., Geffers, R., Sriprakash, K. S., et al. (2007). Virulence profiling of Streptococcus dysgalactiae subspecies equisimilis isolated from infected humans reveals 2 distinct genetic lineages that do not segregate with their phenotypes or propensity to cause diseases. Clin. Infect. Dis. 44, 1442-1454. doi: 10.1086/516780

Davies, M. R., Shera, J., Van Domselaar, G. H., Sriprakash, K. S., and McMillan, D. J. (2009). A novel integrative conjugative element mediates genetic transfer from group G Streptococcus to other beta-hemolytic streptococci. J. Bacteriol. 191, 2257-2265. doi: 10.1128/JB.01624-08

Dinkla, K., Nitsche-Schmitz, D. P., Barroso, V., Reissmann, S., Johansson, H. M., Frick, I. M., et al. (2007). Identification of a streptococcal octapeptide motif involved in acute rheumatic fever. J. Biol. Chem. 282, 18686-18693. doi: 10.1074/jbc.M701047200

Dinkla, K., Rohde, M., Jansen, W. T., Kaplan, E. L., Chhatwal, G. S., and Talay, S. R. (2003). Rheumatic fever-associated Streptococcus pyogenes isolates aggregate collagen. J. Clin. Invest. 111, 1905-1912. doi: 10.1172/JCI17247

Duesberg, C. B., Malhotra-Kumar, S., Goossens, H., Mcgee, L., Klugman, K. P., Welte, T., et al. (2008). Interspecies recombination occurs frequently in quinolone resistance-determining regions of clinical isolates of Streptococcus pyogenes. Antimicrob. Agents Chemother. 52, 4191-4193. doi: 10.1128/AAC.00518-08

Efstratiou, A. (1997). Pyogenic streptococci of Lancefield groups C and G as pathogens in man. Soc. Appl. Bacteriol. Symp. Ser. 26, 72S-79S. doi: 10.1046/j.1365-2672.83.s1.8.x 
Enright, M. C., Spratt, B. G., Kalia, A., Cross, J. H., and Bessen, D. E. (2001). Multilocus sequence typing of Streptococcus pyogenes and the relationships between emm type and clone. Infect. Immun. 69, 2416-2427. doi: 10.1128/IAI.69.4.24162427.2001

Facklam, R. (2002). What happened to the streptococci: overview of taxonomic and nomenclature changes. Clin. Microbiol. Rev. 15, 613-630. doi: 10.1128/CMR.15.4.613-630.2002

Fernie-King, B. A., Seilly, D. J., and Lachmann, P. J. (2004). The interaction of streptococcal inhibitor of complement (SIC) and its proteolytic fragments with the human beta defensins. Immunology 111, 444-452. doi: 10.1111/j.00192805.2004.01837.x

Fernie-King, B. A., Seilly, D. J., Willers, C., Wurzner, R., Davies, A., and Lachmann, P. J. (2001). Streptococcal inhibitor of complement (SIC) inhibits the membrane attack complex by preventing uptake of C567 onto cell membranes. Immunology 103, 390-398. doi: 10.1046/j.1365-2567.2001.01249.x

Frick, I. M., Nordin, S. L., Baumgarten, M., Morgelin, M., Sorensen, O. E., Olin, A. I., et al. (2011). Constitutive and inflammation-dependent antimicrobial peptides produced by epithelium are differentially processed and inactivated by the commensal Finegoldia magna and the pathogen Streptococcus pyogenes. J. Immunol. 187, 4300-4309. doi: 10.4049/jimmunol. 1004179

Galperine, T., Cazorla, C., Blanchard, E., Boineau, F., Ragnaud, J. M., and Neau, D. (2007). Streptococcus canis infections in humans: retrospective study of 54 patients. J. Infect. 55, 23-26. doi: 10.1016/j.jinf.2006.12.013

Green, N. M., Zhang, S., Porcella, S. F., Nagiec, M. J., Barbian, K. D., Beres, S. B., et al. (2005). Genome sequence of a serotype M28 strain of group a Streptococcus: potential new insights into puerperal sepsis and bacterial disease specificity. J. Infect. Dis. 192, 760-770. doi: 10.1086/430618

Haidan, A., Talay, S. R., Rohde, M., Sriprakash, K. S., Currie, B. J., and Chhatwal, G. S. (2000). Pharyngeal carriage of group C and group G streptococci and acute rheumatic fever in an Aboriginal population. Lancet 356, 1167-1169. doi: 10.1016/S0140-6736(00)02765-3

Horstmann, R. D., Sievertsen, H. J., Knobloch, J., and Fischetti, V. A. (1988). Antiphagocytic activity of streptococcal M protein: selective binding of complement control protein factor H. Proc. Natl. Acad. Sci. U.S.A. 85, 1657-1661. doi: 10.1073/pnas.85.5.1657

Ikebe, T., Murayama, S., Saitoh, K., Yamai, S., Suzuki, R., Isobe, J., et al. (2004). Surveillance of severe invasive group-G streptococcal infections and molecular typing of the isolates in Japan. Epidemiol. Infect. 132, 145-149. doi: $10.1017 /$ S0950268803001262

Johnsson, E., Berggard, K., Kotarsky, H., Hellwage, J., Zipfel, P. F., Sjobring, U., et al. (1998). Role of the hypervariable region in streptococcal M proteins: binding of a human complement inhibitor. J. Immunol. 161, 4894-4901.

Johnsson, E., Thern, A., Dahlback, B., Heden, L. O., Wikstrom, M., and Lindahl, G. (1996). A highly variable region in members of the streptococcal M protein family binds the human complement regulator C4BP. J. Immunol. 157, 30213029.

Kalia, A., and Bessen, D. E. (2003). Presence of streptococcal pyrogenic exotoxin A and $\mathrm{C}$ genes in human isolates of group G streptococci. FEMS Microbiol. Lett. 219, 291-295. doi: 10.1016/S0378-1097(03)00022-3

Kalia, A., and Bessen, D. E. (2004). Natural selection and evolution of streptococcal virulence genes involved in tissue-specific adaptations. J. Bacteriol. 186, 110 121. doi: 10.1128/JB.186.1.110-121.2004

Kapur, V., Kanjilal, S., Hamrick, M. R., Li, L. L., Whittam, T. S., Sawyer, S. A., et al. (1995). Molecular population genetic analysis of the streptokinase gene of Streptococcus pyogenes: mosaic alleles generated by recombination. Mol. Microbiol. 16, 509-519. doi: 10.1111/j.1365-2958.1995.tb02415.x

Kawamura, Y., Fujiwara, H., Mishima, N., Tanaka, Y., Tanimoto, A., Ikawa, S., et al. (2003). First Streptococcus agalactiae isolates highly resistant to quinolones, with point mutations in gyrA and parC. Antimicrob. Agents Chemother. 47, 36053609. doi: 10.1128/AAC.47.11.3605-3609.2003

Lai, Y., and Gallo, R. L. (2009). AMPed up immunity: how antimicrobial peptides have multiple roles in immune defense. Trends Immunol. 30, 131-141. doi: 10.1016/j.it.2008.12.003

Lefebure, T., Richards, V. P., Lang, P., Pavinski-Bitar, P., and Stanhope, M. J. (2012). Gene repertoire evolution of Streptococcus pyogenes inferred from phylogenomic analysis with Streptococcus canis and Streptococcus dysgalactiae. PLoS ONE 7:e37607. doi: 10.1371/journal.pone.0037607
Lizano, S., Luo, F., and Bessen, D. E. (2007). Role of streptococcal T antigens in superficial skin infection. J. Bacteriol. 189, 1426-1434. doi: 10.1128/JB.01179-06

Lo, H. H., and Cheng, W. S. (2014). Distribution of virulence factors and association with emm polymorphism or isolation site among betahemolytic group G Streptococcus dysgalactiae subspecies equisimilis. APMIS. doi: 10.1111/apm.12305 [Epub ahead of print].

Maxted, W. R., and Potter, E. V. (1967). The presence of type 12 M-protein antigen in group G streptococci. J. Gen. Microbiol. 49, 119-125. doi: 10.1099/0022128749-1-119

McArthur, J. D., Mckay, F. C., Ramachandran, V., Shyam, P., Cork, A. J., SandersonSmith, M. L., et al. (2008). Allelic variants of streptokinase from Streptococcus pyogenes display functional differences in plasminogen activation. FASEB J. 22, 3146-3153. doi: 10.1096/fj.08-109348

McMillan, D. J., Bessen, D. E., Pinho, M., Ford, C., Hall, G. S., Melo-Cristino, J., et al. (2010). Population genetics of Streptococcus dysgalactiae subspecies equisimilis reveals widely dispersed clones and extensive recombination. PLoS ONE 5:e11741. doi: 10.1371/journal.pone.0011741

McMillan, D. J., Kaul, S. Y., Bramhachari, P. V., Smeesters, P. R., Vu, T., Karmarkar, M. G., et al. (2011). Recombination drives genetic diversification of Streptococcus dysgalactiae subspecies equisimilis in a region of streptococcal endemicity. PLoS ONE 6:e21346. doi: 10.1371/journal.pone.0021346

Minami, M., Ichikawa, M., Matsui, H., Hata, N., Wakiyama, N., Matsumoto, M., et al. (2011). Prevalence of a streptococcal inhibitor of a complement-mediated cell lysis-like gene ( Microbiol. 62, 884-887. doi: 10.1007/s00284-010-9798-8

Mora, M., Bensi, G., Capo, S., Falugi, F., Zingaretti, C., Manetti, A. G., et al. (2005). Group A Streptococcus produce pilus-like structures containing protective antigens and Lancefield T antigens. Proc. Natl. Acad. Sci. U.S.A. 102, 15641-15646. doi: $10.1073 /$ pnas.0507808102

O’Loughlin, R. E., Roberson, A., Cieslak, P. R., Lynfield, R., Gershman, K., Craig, A., et al. (2007). The epidemiology of invasive group A streptococcal infection and potential vaccine implications: United States, 2000-2004. Clin. Infect. Dis. 45, 853-862. doi: 10.1086/521264

Oppegaard, O., Mylvaganam, H., Skrede, S., Langeland, N., and Kittang, B. R. (2014). Sequence diversity of sicG among group C and G Streptococcus dysgalactiae subspecies equisimilis isolates associated with human infections in western Norway. Eur. J. Clin. Microbiol. Infect. Dis. 33, 273-277. doi: 10.1007/s10096013-1955-0

Palmieri, C., Magi, G., Creti, R., Baldassarri, L., Imperi, M., Gherardi, G., et al. (2013). Interspecies mobilization of an ermT-carrying plasmid of Streptococcus dysgalactiae subsp. equisimilis by a coresident ICE of the ICESa2603 family. J. Antimicrob. Chemother. 68, 23-26. doi: 10.1093/jac/dks352

Palmieri, C., Magi, G., Mingoia, M., Bagnarelli, P., Ripa, S., Varaldo, P. E., et al. (2012). Characterization of a Streptococcus suis tet(O/W/32/O)-carrying element transferable to major streptococcal pathogens. Antimicrob. Agents Chemother. 56, 4697-4702. doi: 10.1128/AAC.00629-12

Palmieri, C., Varaldo, P. E., and Facinelli, B. (2011). Streptococcus suis, an emerging drug-resistant animal and human pathogen. Front. Microbiol. 2:235. doi: 10.3389/fmicb.2011.00235

Panchaud, A., Guy, L., Collyn, F., Haenni, M., Nakata, M., Podbielski, A., et al. (2009). M-protein and other intrinsic virulence factors of Streptococcus pyogenes are encoded on an ancient pathogenicity island. BMC Genomics 10:198. doi: 10.1186/1471-2164-10-198

Pinho, M. D., Melo-Cristino, J., and Ramirez, M. (2006). Clonal relationships between invasive and noninvasive Lancefield group $\mathrm{C}$ and $\mathrm{G}$ streptococci and emm-specific differences in invasiveness. J. Clin. Microbiol. 44, 841-846. doi: 10.1128/JCM.44.3.841-846.2006

Pletz, M. W., Mcgee, L., Van Beneden, C. A., Petit, S., Bardsley, M., Barlow, M., et al. (2006). Fluoroquinolone resistance in invasive Streptococcus pyogenes isolates due to spontaneous mutation and horizontal gene transfer. Antimicrob. Agents Chemother. 50, 943-948. doi: 10.1128/AAC.50.3.943-948.2006

Powis, J., Mcgeer, A., Duncan, C., Goren, R., De Azavedo, J. C., Bast, D. J., et al. (2005). Prevalence and characterization of invasive isolates of Streptococcus pyogenes with reduced susceptibility to fluoroquinolones. Antimicrob. Agents Chemother. 49, 2130-2132. doi: 10.1128/AAC.49.5.2130-2132.2005

Reinert, R. R., Lutticken, R., and Al-Lahham, A. (2004). High-level fluoroquinolone resistance in a clinical Streptococcus pyogenes isolate in Germany. Clin. Microbiol. Infect. 10, 659-662. doi: 10.1111/j.1469-0691.2004.00890.x 
Sachse, S., Seidel, P., Gerlach, D., Gunther, E., Rodel, J., Straube, E., et al. (2002). Superantigen-like gene(s) in human pathogenic Streptococcus dysgalactiae, subsp. equisimilis: genomic localisation of the gene encoding streptococcal pyrogenic exotoxin G (speG(dys)). FEMS Immunol. Med. Microbiol. 34, 159167. doi: 10.1111/j.1574-695X.2002.tb00618.x

Simpson, W. J., Musser, J. M., and Cleary, P. P. (1992). Evidence consistent with horizontal transfer of the gene (emm12) encoding serotype M12 protein between group A and group $\mathrm{G}$ pathogenic streptococci. Infect. Immun. 60, 18901893.

Simpson, W. J., Robbins, J. C., and Cleary, P. P. (1987). Evidence for group Arelated $\mathrm{M}$ protein genes in human but not animal-associated group $\mathrm{G}$ streptococcal pathogens. Microb. Pathog. 3, 339-350. doi: 10.1016/0882-4010(87) 90004-0

Sitkiewicz, I., Green, N. M., Guo, N., Mereghetti, L., and Musser, J. M. (2011). Lateral gene transfer of streptococcal ICE element RD2 (region of difference 2) encoding secreted proteins. BMC Microbiol. 11:65. doi: 10.1186/1471-2180$11-65$

Smyth, D., Cameron, A., Davies, M. R., Mcneilly, C., Hafner, L., Sriprakash, K. S., et al. (2014). DrsG from Streptococcus dysgalactiae subsp. equisimilis inhibits the antimicrobial peptide LL-37. Infect. Immun. 82, 2337-2344. doi: 10.1128/IAI.01411-13

Sriprakash, K. S., and Hartas, J. (1996). Lateral genetic transfers between group A and G streptococci for M-like genes are ongoing. Microb. Pathog. 20, 275-285. doi: 10.1006/mpat.1996.0026

Suzuki, H., Lefebure, T., Hubisz, M. J., Pavinski Bitar, P., Lang, P., Siepel, A., et al. (2011). Comparative genomic analysis of the Streptococcus dysgalactiae species group: gene content, molecular adaptation, and promoter evolution. Genome Biol. Evol. 3, 168-185. doi: 10.1093/gbe/evr006

Tewodros, W., Karlsson, I., and Kronvall, G. (1996). Allelic variation of the streptokinase gene in beta-hemolytic streptococci group C and G isolates of human origin. FEMS Immunol. Med. Microbiol. 13, 29-34.

Towers, R. J., Gal, D., McMillan, D., Sriprakash, K. S., Currie, B. J., Walker, M. J., et al. (2004). Fibronectin-binding protein gene recombination and horizontal transfer between group A and G streptococci. J. Clin. Microbiol. 42, 5357-5361. doi: 10.1128/JCM.42.11.5357-5361.2004
Tsai, C. T., Chi, C. Y., Ho, C. M., Lin, P. C., Chou, C. H., Wang, J. H., et al. (2013). Correlation of virulence genes to clinical manifestations and outcome in patients with Streptococcus dysgalactiae subspecies equisimilis bacteremia. J. Microbiol. Immunol. Infect. doi: 10.1016/j.jmii.2013.08.019 [Epub ahead of print].

Watanabe, S., Kirikae, T., and Miyoshi-Akiyama, T. (2013). Complete genome sequence of Streptococcus dysgalactiae subsp. equisimilis 167 carrying Lancefield group $\mathrm{C}$ antigen and comparative genomics of $S$. dysgalactiae subsp. equisimilis strains. Genome Biol. Evol. 5, 1644-1651. doi: 10.1093/gbe/ evt117

Wehbeh, W., Rojas-Diaz, R., Li, X., Mariano, N., Grenner, L., Segal-Maurer, S., et al. (2005). Fluoroquinolone-resistant Streptococcus agalactiae: epidemiology and mechanism of resistance. Antimicrob. Agents Chemother. 49, 2495-2497. doi: 10.1128/AAC.49.6.2495-2497.2005

Zheng, Y., Roberts, R. J., and Kasif, S. (2004). Segmentally variable genes: a new perspective on adaptation. PLoS Biol. 2:e81. doi: 10.1371/journal.pbio. 0020081

Conflict of Interest Statement: The authors declare that the research was conducted in the absence of any commercial or financial relationships that could be construed as a potential conflict of interest.

Received: 07 October 2014; accepted: 19 November 2014; published online: 15 December 2014.

Citation: McNeilly CL and McMillan DJ (2014) Horizontal gene transfer and recombination in Streptococcus dysgalactiae subsp. equisimilis. Front. Microbiol. 5:676. doi: 10.3389/fmicb.2014.00676

This article was submitted to Antimicrobials, Resistance and Chemotherapy, a section of the journal Frontiers in Microbiology.

Copyright (C) 2014 McNeilly and McMillan. This is an open-access article distributed under the terms of the Creative Commons Attribution License (CC BY). The use, distribution or reproduction in other forums is permitted, provided the original author(s) or licensor are credited and that the original publication in this journal is cited, in accordance with accepted academic practice. No use, distribution or reproduction is permitted which does not comply with these terms. 